\title{
ICT in Auditing: Impact of Audit Quality Norms on Interpersonal Interactions
}

\author{
Slobodan Kacanski*
}

\begin{abstract}
:
Productivity incentives have lately been driving auditors to introduce and utilize various computer-based tools to assist their work. The aim of this study is to understand how and why productivity incentives may disturb interpersonal interaction and relations between auditors at different ranks, in the context of assurance service. A case study was carried out with auditors affiliated with Danish subsidiaries of Big 4 audit firms to inspect the implementation and utilization of global audit methodology (GAM), which is the ICT-based platform that guides subordinate auditors through the audit process. The results highlight that superior auditors tend to experience prevalent trust in ICT tool over subordinate auditors, where such conditions reduce the opportunity for experiencing comfort by subordinates, while superiors still perceive comfort due to being comfortable with procedures that are administered by the tool. Finally, this mechanism further creates conditions under which the necessity for establishing interactions and relations between auditors of different ranks become diminished.
\end{abstract}

Key words: Global audit methodology; Information and communication technologies; Audit quality; Interactions.

JEL classification: M42.

\section{Introduction}

A continuously intertwining tension between cuts of audit fees, incentives to increase productivity, efficiency, and effectiveness and ensuring good quality of audit reports, characterizes the today's world of the assurance service. In order to mitigate possible negative consequences of financial pressures due to higher audit fees but to retain institutional legitimacy, audit firms tend to advance auditing methodology by integrating information and communication technologies (ICT) (Manson, McCartney, \& Sherer, 2001). However, the omnipresence of the ICT in audit firms and utilization of computer-assisted audit tools and techniques (CAATTs) has generated a broad range of consequences on the carriers of a profession as well to the profession as such.

Over the past decades, two research streams were segregated in connection with roles and impacts that ICT brought to audit profession and auditors as carriers of the profession. On the one hand, literature indicated that audit firms tend to turn to the ICT in order to increase work efficiency and quality of the audit reports, which

Slobodan Kacanski; Roskilde University, Department of Social Sciences and Business, Management and organization, Universitetsvej 1, 4000 Roskilde, Denmark, <kacanski@ ruc.dk>. 
they use as a tool to yield bigger profits while shortening the engagement time and servicing more clients in a unit of time (Abdolmohammadi \& Usoff, 2001; Banker, Chang, \& Kao, 2002; Janvrin, Bierstaker, \& Lowe, 2008, Elliot, Kielich, \& Marwick, 1985). Additionally, literature shows that socially designed technology (Berg, 1998) provides a wide range of audit tools that may support almost any audit task that span from data extraction to data analysis (Pedrosa \& Costa, 2012), which contributes to productivity and disburdening auditors, but also reducing the level of auditors' responsibilities.

The second group of studies revealed that utilization of auditing tools during audit engagement might moderate the structure and sequence of auditing procedures. Thus, ICT-based audit tools have potential to facilitate auditors' thoughts (Pieptea \& Anderson, 1987) through which the ICT generates a list of tasks that keeps auditor's focus to those that are estimated to be essential for a particular engagement (Abdolmohammadi \& Usoff, 2001). Glover, Prawitt \& Spilker (1997) argued that ICT relaxes the need for professional assistance for newcomers as tools enable relatively inexperienced auditors to approach tasks mechanistically. However, besides the simplification, literature stressed that technology may affect auditor's judgment and impact the quality of final reasoning (Bonner, 1999; Bell et al., 2002) as auditor's judgment may be moderated by technologically predetermined procedures, which consequently may constrain appearance of multiple opinions (O’Leary \& Watkins, 1989) and discourage professional discussions. All these have raised an additional concern about the consequences that utilization of ICT in auditing had on generating professional judgment since profit incentives, efficiency and effectiveness gains, and cost reductions, notably affected auditors' judgmental and decision-making skills (Adler, 1987). In the overall, literature emphasized that integration of the ICT-based audit tools both enhances auditor's performance by increasing productivity and efficiency of their work, but also may propel the issue of deskilling professionals, as according to Swinney (1999) auditors that use ICT tend to over-rely on technologically generated output. However, a comparative study by Brazel, Agoglia \& Hatfield (2004) showed that even though ICT increases efficiency, auditors that manually conducted audit engagement tend to feel more accountable to their correspondents in relation with delivered opinion, which proves that judgment is merely a cognitive process, and may create the feeling of importance. This extends Pentland's (1993) argument that auditor judgment, besides of cognitive, is also a result of an emotional resource when a feeling of comfort gives an additional input to the auditor while constructing the opinion. This implies that professional judgment is comprised of both cognitive and emotional parts, which both are personal. In relation to this, I assert that due to technology, the possibility of experiencing comfort becomes significantly diminished as technologies and audit tools are becoming more reliable carriers of the audit profession. 
Despite that previous research provided with some of the critical reflections on the utilization of ICT in auditing on various aspects, the literature has not yet observed how the use of technologies influenced differently ranked auditors. Also, studies neglected to inspect whether and how perceptions about ICT differ across various audit levels. To overcome the limitations of previous studies I introduce an alternative theoretical background to serve as a tool that has the capacity to challenge previous two streams of literature through the case study that will enable putting incentives for productivity and comfort-related deskilling effects into the foundation of current tensions that are observable in the audit profession. Therefore, study here concentrates on how mechanisms of trust in carriers of the profession, ICT, and humans, mutually challenge one another. According to this, I argue that superiors and subordinates are expected to have dissimilar perceptions of implications of the ICT that could, in auditing context, be ascribed to comfort, which might consequently impact the social interaction between auditors belonging to different professional ranks.

In particular, this study focuses on how both subordinated audit staff, which the make use of technology, and superiors that hold productivity incentives, but do not utilize it, individually perceive (1) the ICT in regards the advantages and disadvantages of their implementation on themselves, and (2) the other audit ranks through the functional properties of the ICT. To put ICT adequately into the research context, I introduce the case of risk-based audit methodology, named global audit methodology (GAM) that has recently been implemented among audit firms at the global level. Integration of GAM into the ICT aims at ensuring a consistent approach to all audit engagements, which provides auditors with guidance through the auditing process. This article has been inspired by Sorensen \& Sorensen (1974) study on conflicts in bureaucratic organizations that were caused by differences in a rank-based professional aims. For the purpose of this study I distinguish two groups of professional ranks: (1) superiors (audit managers and partners) and (2) subordinates (interns, junior and senior auditors) from the Danish context of Big 4 audit firms. Through the qualitative, cross-sectional investigation, this study exposes the unfolding of sources of a focal entity to answer the following research question:

How and why does the implementation of GAM into ICT impact the relationship between superiors and subordinates in Danish auditing context?

Finally, previous literature has primarily emphasized empirical implications of information technologies from the holistic organizational perspective irrespective to the theory used (Bierstaker, Burnaby, \& Thibodeau, 2001; Brazel et al., 2004; Dowling \& Leech, 2007; Dowling, 2009; Manson et al., 2001; Omoteso, Patel, \& Scott, 2010), whose limitations tend to be overcome in this paper. Studies have 
discussed particular implications and consequences of ICT regardless of potential divergences that might be apparent at different professional ranks.

In this study, the unit of analysis are events, happenings, and incidents (Charmaz, 2006; Corbin \& Strauss, 1990; Glaser \& Strauss, 1967). They are isolated from each participant in order to be studied, which are afterward coupled into two chunks based on participant's affiliation to the particular audit rank in order to extract theoretically grounded coincidences that are ultimately mutually challenged for identification of structural incompliance.

The article proceeds as follows. The introduction presents the background and the research question of the study. The second section outlines theoretical background including the main concepts of the research. The third section delineates the main methodology behind the study, including an elaboration of the empirical context. This is followed by the analysis of the findings. The final section provides a discussion of the results, concluding remarks and limitations of the research.

\section{Theoretical background}

This section proposes theoretical standpoint of the study by concentrating on Giddens (1990) conceptualization of modern social order that will further serve as a tool for understanding tensions at the focal social context. Giddens (1990) propounded a theory of institutional analysis of modernity associating the concept of modernity with time period and location of a current. The concept of modernity refers to modes of social life that are no longer driven by manufacturing system since current institutional transformations have moved the system towards the one centrally concerned with information. That information-based system implies that information organize the social order as they moderate interactions between social actors.

Marx and Durkheim preceded development of theory of modernity where both saw modern era as troubled, but believed that benefits would outweigh its negative characteristics. But Giddens' (1990) theory had substantially different point of origin located in a term of discontinuity. The term was unrelated to historical materialism - as a transition from one form of social system to another, but included the following features: pace of change, scope of change and intrinsic nature of modern institutions. For Giddens, modernity is multidimensional on the level of institution.

Society (and sociology) is an important but ambiguous concept that carries the central notion of 'boundedness' of a social system that has an objective to solve the problem of social order. According to Giddens, the problem of social order in modern societies directs attention on how social system "bind" time and space. He sees the social order through "distanciation" of space and time, which is a condition based on which these two connect presence and absence, so it is 
essential to understand how modern institutions are situated in the particular space and time. A term of institution here refers to inter-subjective interactions, form and nature of that relation. The notion of distanciation enabled him to argue that every social interaction at the very encounter has its ordinance in distance. This implies that any present social interaction, in a variety of social contexts, is distantly molded through its institutionalized form, i.e. no encounter is organized at the spot of occurrence but its nature is already specified somewhere before. Therefore, materialization of social interactions occurs only at the encounter, but the character of it is both enabled and directed outside of that encounter through different forms of standardization. Unlike the traditional approach, in this way conceptualized modernity has capacity to connect local and global up to previously traditionally unthinkable perspectives. The core of this theory of modernity is in two interconnected mechanisms that hold distinctive properties and which could be identified in any context that involves social interaction. Put forward by Antony Giddens (1990) the theory of modernity conjectures the existence of two mechanisms that drive almost any social interaction: disembedding and reembedding.

Firstly, disembedding is a mechanism that "lifts out" the locality of social relation and restructures it across an indefinite span of time and space (Giddens, 1990, p. 21). Therefore, social practices are removed from immediacies of context, and their localized experience becomes shaped through impersonal and abstract processes that occur on the other side of the world (Stones, 2012). When interactions do not take place, disembedding mechanisms would not reify but they will still exist, however, only in their abstract forms. An objective of these mechanisms is to explicate a power of modern institutions to shape the nature of interactions at the global extent and secure social order.

Disembedding is a necessary condition (Stones, 2012) for spreading two impersonal and abstract mechanisms central to dynamics of modernity, namely: (a) symbolic tokens, and (b) expert systems (Giddens, 1990, p. 22). Both of these mechanisms take a role in coordinating social interactions between distant and the absent others.

Symbolic tokens are media of interchange based on which social interactions are regulated. They are spread around in a form of regulations, which apply only to those social actors that materialize particular form of interaction at a particular time. Symbolic tokens have a function to standardize expectations and possible outcomes of social interactions and prohibit unethical actions. On the other hand, expert systems are systems of professional expertise and technical accomplishments that enable purposeful social interaction to occur, such as establishing relations with lawyers, architects etc. (Giddens, 1990, pp. 24-7). Thus, expert systems are capacitated to organize large areas of material and social 
environment where social interactions occur. Coupled together, both symbolic token and expert system assemble the abstract system.

Abstract systems require trust in both of its constitutive elements. In particular, trust in a symbolic token is shared and grounded on the abstract capacities of what couples individuals at the encounter. It does not create trust in individuals as a "whole", but only to those "parts" of individuals that share the same values in the abstract mechanism during the interaction. But, expert systems are based on the faith in the professional expertise that is continuously developed. Giddens argues that the nature of the modern interaction is deeply bound with the trust in abstract systems, but particularly in the part of it related to the expert system (Giddens, 1990, p. 83).

Giddens (1990) couples the previous mechanism with one of reembedding. He argues that reembedding mechanism is a reappropriation or contextualization of previously distantly specified interaction to its already predetermined form. Therefore, reembedding mechanism (Giddens, 1990, p. 79) pins down all of the elements of the abstract system to the encounter where interaction between social actors becomes materialized, as it suggests the nature and the content of realization.

Reembedding mechanism distinguishes two commitments: facework and faceless. Facework commitment refers to a personalized trust that exists and becomes experienced by social actors when the encounter occurs. Faceless commitment refers to the concerns of development of faith in the abstract system. In order to achieve functional appropriation of disembedding and reembedding mechanisms, Giddens (1990) emphasizes the importance of trust in abstract systems. The level of trust enables social actors to estimate costs and benefits of a particular expert system, the selection and potential utilization of it.

This theoretical approach is selected as it enables observing of how trusts in different abstract systems, which are integrated into the same context, challenge social interactions. Concretely, these mechanisms enable analysis of relationships between superiors and subordinates whose interaction has been challenged by prevailing trust in an alternative abstract system that became reembedded in the contextual setting.

In particular, the moderating effect of the abstract system at the social encounter is the main mechanism that is in the focus of an empirical setting. The twodimensional approach that integrates mutually interactive mechanisms is found to be conductive for a proper approach to the issues that try-outs of trust in a modern assembly of social interactions may have on human agency at the professional encounter. I believe that this analytical framework provides with an adequate approach to understanding how trust in distantly regulated procedures and technological accomplishments actually produce negotiation of trust in human 
carriers of the profession at the focal context of auditing, which ultimately influenced relations.

\section{Methodology}

\section{Grounded theory and theory building from case study research}

In this study, I adopted a grounded theory approach as it allows determining the sequence of necessary steps and tasks in the process of conceptualization and identification of relations between concepts in newly established working environment of assurance services in international audit firms. Corbin and Strauss (1990) argued that qualitative methods could be systematically evaluated only if procedures and canons are made explicit. They have proposed canons of a 'good science' as a procedure that should be followed to help a researcher to develop a well-integrated set of concepts, which will provide the theoretical explanation of social phenomena under study. Since the literature on implementation and use of ICT in audit services have already recognized several core concepts that resulted from implications that technology made on auditing and auditors (Abdolmohammadi \& Usoff, 2001; Banker et al., 2002; Bierstakeret al., 2001; Janvrin et al., 2008), the canons of grounded theory here aim at serving as a tool for extending and as well understanding relations between concepts.

To ensure a systematic approach to answering the research question, I draw on some research tools from grounded theory depicted by Corbin \& Strauss (1990, 2008) and the case-study methodology by Eisenhardt (1989) to guide theorybuilding from case study research. First of all, a structured literature review was carried out in order to (1) set the grounds for the investigation; (2) identify objectives of the research, and (3) specify a priori construct (Eisenhardt 1989). I then selected the empirical context for the investigation, and entered the field for the data collection and analysis, as described in the following paragraphs.

\section{The empirical context: Assurance services}

An auditing service context of international audit firms, particularly Big 4, is in the focus of this study. Generally speaking, that service provides an independent inspection of annual and other financial accounts, and gives the assurance on whether those financial reports, that are objects of inspection, give a true and fair representation of a business entity.

A today's world of the assurance service is characterized by the omnipresence of information and communication technologies in work of auditors, because they have supporting nature and enable productivity and efficiency gains. Since ICT continuously develop and change, their permanent presence in research is crucial, particularly as they might affect a variety of other social phenomena. This particularly refers to the importance of conducting investigations of effects that technological advancement has on those that make the use of them (Orlikowski \& 
Iacono, 2001), yet observed from particular empirical context. Assurance service is characteristic as teams that conduct particular audit engagement are assembled of members that belong to diverse professional ranks, from junior auditors to audit partners, where the number of those involved in single engagement depends on client's paperwork complexity. Since the extent to what auditors use ICT differs across the ranks, the implications that technologies have on their subjective perception of consequences that ICT have on their work, might be significantly different between them.

However, to tackle the research question, I selected the assurance service as a type of auditing and consulting services that Big 4 auditing firms provide. In order to bring theoretically extensive construct of ICT closer to empirical examination, I utilized global audit methodology (GAM) to scrutinize implications of ICT on auditors. Global audit methodology is a risk-based methodology (Robson et al., 2007) that has recently started to be used by international audit firms as a tool to enable delivering same proven approach and ensure quality to every audit engagement across their subsidiaries at the global level. The methodology is not only a standalone or a standard-like guide of predetermined procedures of engagement, but it is rather operationalized by cutting-edge technology as it is integrated within. Furthermore, the methodology is a cloud-based roadmap that is capacitated to organize the majority of auditor's work as it suggests steps, tests, and tasks that auditors should conduct to fulfill requirements of a single engagement. The methodology is composed of four groups of processes where each contains the list of tasks, which are related to single engagement: (1) planning and risk identification; (2) strategy and risk assessment; (3) execution; and (4) conclusion and reporting, which are compliant to ISA 315 "Identifying and assessing the risk of material misstatements through understanding the entity and its environment" (ISA 315, 2009). In order to adapt empirical interrogation of implications that ICT has on auditors, I put ICT in the function of GAM to a particular case of research.

As audit requires a specified list of tasks to be performed by members of the engagement team, which may range from the computer-based mundane, to personto-person negotiations, an involvement of auditors of diverse ranks is a prerequisite. Since diverse auditors might appear to have own perceptions and expectations about the ICT, they might appear to be similar within the same group, and different between heterogeneous groups, so the examination of implications across team members will open discussion on how different perceptions affect their interaction and relation.

\section{Data collection and data analysis}

I selected qualitative research methods as they adequately correspond to a perspective of emphasizing perceptions and expectations rather than variables, 
which are specific for alternative research methods. I collected cross-sectional data by combining interviews with archive data, as according to Langley et al. (2013) archive data may support interview data for tracing meanings of facts that were previously emphasized in discussions. For this study, I conducted qualitative interviews (Yin, 2011:133) particularly in-depth interviews (Weiss, 1994), which is qualitative research technique for conducting intensive and less structured interviews with a small number of participants about ideas, programs or situations (Boyce \& Neale, 2006). In-depth interview technique enables collecting detailed data on changes that participants perceive in themselves that are the result of their involvement in a particular case, or if new issues are of main concern to researcher and they need to be explored in depth (Boyce \& Neale, 2006). The interview data were supported by archive data that are collected primarily from interviewees, but also from secondary sources (Internet).

The sample of selected participants (Table 1) was taken from the population belonging to the Danish field of the assurance services of Big 4 audit firms to control for environmental variations and clarify the domain of findings to auditing (Eisenhardt, 1989; Eisenhardt \& Graebner, 2007). Theoretical sampling was carried out in two subsequent phases. The first phase of interviewees sampling took place on convenience that was further followed by snowball sampling, which ensured overcoming of limitations that initial phases of data collection challenged (Eisenhardt, 1989). The study included in total 16 in-depth semi-structured interviews based on open-ended questions from five audit ranks from representatives of each Big 4 audit firm followed by archive documents to support the analysis and understanding the meaning of discussions.

\section{Tab. 1: The sample of selected participants}

\begin{tabular}{llrr}
\hline Audit firm number & Audit rank & $\begin{array}{l}\text { Number of } \\
\text { interviewees }\end{array}$ & $\begin{array}{l}\text { Interview } \\
\text { number (ID) }\end{array}$ \\
\hline \multirow{3}{*}{1} & Manager & 1 & 1 \\
& Senior & 1 & 2 \\
& Intern & 2 & 3,4 \\
\hline \multirow{3}{*}{2} & Partner & 1 & 5 \\
& Manager & 1 & 6 \\
& Senior & 1 & 7 \\
3 & Junior & 1 & 8 \\
\hline \multirow{3}{*}{} & Partner & 1 & 9 \\
& Senior & 1 & 10 \\
& Junior & 2 & 11,12 \\
& Intern & 1 & 13 \\
\hline
\end{tabular}


Kacanski, S.: $\quad$ ICT in Auditing: Impact of Audit Quality Norms on Interpersonal Interactions.

\begin{tabular}{llrr}
\hline Audit firm number & Audit rank & $\begin{array}{l}\text { Number of } \\
\text { interviewees }\end{array}$ & $\begin{array}{l}\text { Interview } \\
\text { number (ID) }\end{array}$ \\
\hline 4 & Manager & 1 & 14 \\
& Senior & 2 & 15,16 \\
\hline Total & & $\mathbf{1 6}$ & \\
\hline
\end{tabular}

Source: authorial computation based on data collection

However, data collection and data analysis were not strictly separated phases, as the data analysis overlapped the data collection (Eisenhardt, 1989). Following the first canon by Corbin and Strauss (1990), I started the analysis as the first bit of data was collected. This approach enabled me to continuously adjust interview protocols prior the forthcoming interview as well during discussions on the basis of the emergence of interesting themes. To aid the data analysis I used NVivo software, v.10.1, to which I transferred the entire database, and implemented lineby-line open and axial coding.

\section{Analysis of findings}

The assurance service, where implementation of global audit methodology into information and communication technologies made consequences on working environment of Big 4 audit firms, are inspected in this study. In particular, this study observed how and why newly established auditing procedures influenced the interaction between auditors of different ranks. Particularly, the case concentrated on various aspects of auditors' perceptions of implications of procedural changes, observed from the Danish context of the assurance service. The set of employees under investigation included five respective audit ranks: (1) intern (student researcher); (2) junior (assistant); (3) senior; (4) manager (including senior manager and executive director), and (5) partner. Despite the fact that audit firms are occupying classification of professionals within seven respective ranks, due to differences in levels of professional responsibilities but relative similarities in relations with the individual audit engagements, I have grouped three managerial levels into the major cluster naming it managers. This categorization has enabled me to identify and understand reflections and differences in perspectives that particular professional rank has in relations to information and communication technologies (ICT), as well to inspect the origins of those similarities that apparent within the groups of participants. Also, I included interns (study researchers) into the study in order to observe their expectations from the professional engagements.

The analysis here delineates the most relevant findings from an examination of the focal case and gives the representation of results through three separate propositions that correspond to the theoretical background. The first proposition gives a general reflection on how auditing process has been affected by the integration of GAM in ICT (further referred as a tool), from interviewees' point of 
view. The second and third propositions provide extensive discussions about the tool since they capture participant's reflections on various aspects of consequences of utilization. However, analysis of findings captures reflections of each five auditing ranks, which due to homogeneity were coupled in two clusters and further distinguished as (1) superiors and (2) subordinates. Despite that different professional ranks carry significantly different level of responsibilities, the classification of ranks into clusters has been made according to the extent of their exposure to the ICT during audit engagements, against which subordinates are very dependent on technologies during the work comparing to superiors. The following table 2 provides with the outline of the structure of interviewees in regards to previous classification and auditors' affiliations.

\section{Tab. 2: Overview of interviewees across audit firms and audit rank clusters}

\begin{tabular}{lrrr}
\hline Audit firm & Superior & Subordinate & In total \\
\hline 1 & 1 & 3 & 4 \\
2 & 2 & 2 & 4 \\
3 & 2 & 3 & 5 \\
4 & 1 & 2 & 3 \\
\hline In total & $\mathbf{6}$ & $\mathbf{1 0}$ & $\mathbf{1 6}$ \\
\hline
\end{tabular}

Source: authorial computation based on data collection.

The former cluster is assembled of audit partners and managers, while the latter was comprised of senior auditors, junior auditors, and interns. Such distinction was legitimate due to inequalities in levels of exposure to the ICT during the engagement, and such clustering enabled me to generalize differences between viewpoints of two groups of professionals.

Proposition 1: Implementation of GAM in ICT increases productivity and ensures maintaining the quality of auditing.

When managements of audit firms announced that new methodology would become an integral part of their future engagement procedures, and will change the nature of their work, they primarily argued that the rational for integration is in the fact that it will contribute to productivity and efficiency of the audit process. Despite that methodology has already existed for some years, and each audit firm has its own unique approach to engagement with clients, in general, the difference it made is that it became integrated into the information technology. Auditors here referred to the global audit methodology either as a tool or software since the methodology became an integral part of already utilized ICT system.

It is communicated that we need to be more efficient, have better software, which will allow us to work faster, smarter and make sure that everyone follows the methodology. (Interview with junior auditor, Audit Firm 2/Interview ID 8) 
Kacanski, S.: $\quad$ ICT in Auditing: Impact of Audit Quality Norms on Interpersonal Interactions.

One of the junior auditors emphasized functional aspects of the tool. The interviewee stated that power of the tool it is in its capacity to control the engagement process as it provides with guidelines and determines steps that each team member should undergo, according to what they are in charge of. The tool aims at automating the sequence of tasks, as it contributes to the reduction of time spent on managing the audit engagement.

GAM is a kind of software that drives you through the procedures that you should do. It is a crucial part of each audit engagement because it is a kind of the roadmap of the entire audit process, with all phases. You just use your software and go step-by-step, and it automatically guides you through the steps and required tasks. GAM is developed just to be in line with that. (Interview with senior auditor, AF1/INT2)

A representative of subordinated audit staff depicts characteristics of the tool by outlining main sections of the interface. The tool organizes auditors' work by keeping the record of performed tasks and enables communication with other engagement team members directly through the system. However, GAM does not integrate tools for executing tests, but it rather organizes tools that are necessary to undergo the process.

It is one big checklist, and it guides you through the process and allows you to document all of your work. Besides the project, the software also incorporates communication. Then, you need to do additional work of verifying calculations, verifying documents, doing all of the analytical analysis on your own or maybe using some other tools. (Interview with intern, AF3/INT13)

At the preambles of the most of the interview discussions, interlocutors grouped to subordinate auditors pointed that GAM, from their general perspective, has a positive influence on productivity and efficiency of engagement. However, they also emphasize that this is the system that represents the core of their work, which shapes the character of a workplace of any subordinated auditor. It is apparent that subordinate auditors are highly reliable to functional capacities of the methodology, as it provides them with the access to instructions and enables easy overview to the current stage of the engagement process, as well the list of remaining tasks.

It is the main tool that we work with, so we use it all the time. It is very efficient and very basic tool, which makes us very productive. (Interview with partner, AF2/INT5)

It seems that general agreement on positive aspects of the tool exists both between superiors and subordinates. Namely, one representative of superior auditors, whose work is therefore not primarily ICT-based, emphasized that the main objective behind the utilization of the tool is the audit quality. They interpret quality as the adequacy of application of international standards on auditing (ISA) 
to the audit process. So the positive aspect of the tool is in its capacity to prevent subordinate auditors to either misinterpret or abandon particular regulatory requirement. As standards are subject to change, the methodology should be changed as well, but the switch to a newer version of standards requires less adaptation time by subordinate staff as updated methodology is instantly available upon integration, which minimizes the chance of committing a mistake.

The reason why we have this is that we want to make sure that we have the right quality, and it is important to us to have the right quality of audit... (They) change methodology every 3 - 4 years somehow, and this is because it is ISA compliant. (Interview with manager, AF4/INT14)

Proposition 2: Superior auditors are more reliable to professional capacities of ICT and GAM than to subordinate staff.

Superior auditors show high reliability in capacities of the tool as it aware them that utilization of it will ensure good audit quality. They perceive the tool as a framework that enables consistency with international standards on auditing during the audit process. As audit procedures need to be in compliance with ISA, and GAM is comprised of procedures that are ISA compliant, superiors stress the importance of following the tool in order to ensure fulfillment of all necessary regulatory requirements. They also emphasize that such a way of working is a brand new practice that should be accepted as the newly established working environment.

GAM is like a frame and it makes sense. We need to be within this frame, and we need to do these details to complete tasks or audit procedures. You get used to it. It is just a way of working. (Interview with manager, AF2/INT6)

Before audit firms implemented the tool, auditors had the essential influence on managing the auditing procedures. As novel methodology altered the role of subordinate auditors, superiors' needs and expectations in relations to the subordinate staff have also changed. A representative of superior audit staff pointed that focal problem of preserving the audit quality is in their subordinates. This is because they may commit mistakes and cause a quality issue if they have a certain level of freedom to navigate through the process. In order to diminish that risk, the tool is capacitated to prevent subordinate staff to manage procedures themselves and undergone tasks that are outside of those prescribed.

It is very important for us to have the right quality in an audit. Earlier, if something went wrong, everybody looked at the auditor and asked: "Why didn't you see this?" Auditors are trained with this GAM to make sure that we don't fail our audits. It is because of the scandals that have been in the past. (Interview with partner, AF3/INT9). 
Kacanski, S.: $\quad$ ICT in Auditing: Impact of Audit Quality Norms on Interpersonal Interactions.

The tool is also capacitated to support subordinate auditors during the audit engagement. The tool enables them to overcome any current uncertainties without communicating with more experienced audit staff. Superiors find that the tool does not ensure quality only by managing the list of tasks, but it also support the staff in relation with any perplexities that might emerge during the process. Seemingly, the tool gives a sense of comfort to superior auditors due to the quality it warrants. GAM gives you some kind of guarantee on the quality, and it does! It does!!! Auditors can look up at the methodology while working. They can access it through the intranet, look up things, search things, for example how to do engagement letters, work papers etc. So, it is all integrated into the tool, and tools are built around that to support the methodology. (Interview with manager, AF1/INT1).

In this regard, GAM prevents audit staff to alter any already prescribed procedure. This gives an additional assurance on quality to superiors, as the system automatically blocks any subordinate's attempt to execute procedures beyond those that are prescribed. In such cases, auditors get an automatic message that in order to commit the change they need to obtain agreement from the operation practice department.

Auditors can't do things differently by themselves. There would be some warning in the program. For doing things differently, they need to get a proof from the operation practice department, which I'm part of. So, they can do that but they need to consult department every time they do something differently. (Interview with manager, AF2/INT6).

The work environment change has brought with remarks on which superiors particularly pointed. Namely, they noticed a lack of motivation among subordinate auditors, especially at the early stages of their professional enrollment. However, they do not discern whether the root of the problem is in the changed working environment, while they only compare endeavor of staff with their own previously experienced endeavors. Also, they noted that besides of the lack of motivation, subordinates tend not to leave an impression of responsible persons.

Usually, they want to check less, that's basically their starting point. "How little can we check?" I don't know if they are lazy, but that's where they start. So, unfortunately, I would think that the starting point is "How little I can do? Education is quite good. But, I think that personality has changed quite a lot comparing to when I started. Now, auditors don't take that much responsibility for their own work. (Interview with manager, AF4/INT14).

But, superiors still show strong enthusiasm in regards the quality of subordinates' professional judgment. They perceive that GAM has not impacted professional judgment and that it still is well-cherished part of the profession. 
I do believe that people still have professional judgment and doing it as well as we did it in the good old days, as I can say that nothing has changed from that perspective. (Interview with partner, AF2/INT5)

However, a representative of audit managers turned to the problem of a high turnover rate among auditors. The rate implies that subordinate auditors do not retain in audit firms for a long time, and superiors claim that a general issue is in a work-life misbalance, which is generally usual for auditors. But that reason is only what subordinates report to their managers at the moment of resignation.

There is a quite high turnover. We have a lot of people resigning. Quite a lot, comparing to earlier! A lot of people are now leaving the company. (Interview with partner, AF3/INT9)

Given that the tool enables users to communicate with each other, it eases the interaction between them as it also potentiates communication with simultaneous access to tests and reports. However, the communication between superiors and subordinate auditors became very depersonalized, and preferences to establish personal communication fade from the perspective of superior auditors. This could be a result of pressures that the need for compliances brought with environmental changes, where the tool controls how practitioners conduct the process, so results are not so much in charge of subordinate auditors, which affects the way communication is established between auditors at different levels.

GAM also has a chat tool. The basic idea of it is to have all the communication about project inside the tool. Everything that is done in the database needs to be accepted by someone else. So it is actually a lot of the ongoing field communication in the software tool. Many of us prefer to review notes when we go through the work and send feedbacks via e-mail to our younger staff. (Interview with manager, AF1/INT1)

Proposition 3: Subordinated auditors experience a decrease of their professional capacities due to exposure to the ICT and GAM.

Representatives of subordinate auditors emphasized several focal issues that utilization of the tool brought to their work. The overriding problem they primarily reflect on is the impairment of professional judgment relevance. In regards to this, one of the interviewees stated that utilization of the tool foreshadows the speed over judgmental skills. This is because professional judgment is a time-consuming process, which increases costs more than the quality since the quality is in the tool than in those that work with the tool.

Basically, GAM takes away all the professional judgment from people and shifts it to filling templates and making sure that every step of the methodology was considered and responded. It drills down to a lot of small things that we need to consider and do quickly. It takes away the joy of comprehensive understanding, 
Kacanski, S.: $\quad$ ICT in Auditing: Impact of Audit Quality Norms on Interpersonal Interactions.

which is why you feel important and intellectually satisfied. (Interview with senior auditor, AF3/INT10)

The utilization of the audit tool also brought to several other reflections, one of which is the perception of the auditing industry from subordinate's angle. Auditors are assured that the industry is going towards technological capacitation instead of developing judgmental skills of human carriers of the profession. Therefore, they see that auditing is turning to a business that rather delivers standardized product instead a subjective opinion. This is because the quality is a reflection of a tool than the human resources, which characterize particular firm or the industry in general.

This is a response to audit fees' drop and switch into the commodity type of business. So, it is not really a consulting type of business but a commodity, and we need to deliver an audit opinion at the lowest price. The issue is that they are trying to squeeze the costs, make it faster and pay less to the people, and replace that with the methodology and software, which kind of makes it, even more, the commodity type. (Interview with senior auditor, AF4/INT16)

In this regard, practitioners perceive that the tool constrains them to manage the audit procedures by giving suggestions on changes, e.g. in terms of a sample size. That means that auditors rather need to focus on completion of tasks than on contributing to the quality of engagements, since they understand that superiors' expectations from them are in completion of procedures than in negotiations with them about getting a permission to extend a sample size through which they would be able to manifest their own professional judgment.

I don't always agree with the methodology, sometimes I think it is overloaded and that it does not add value for clients. Even though I would like to do some things differently as I have my own professional skepticism, in GAM, we are just asked to take like 20 samples. But why 20, why not 15 or 25? (Interview with junior auditor, AF3/INT11)

From subordinates' perspective, not only that continuously increased presence of technology reduces the opportunity to prove own judgmental capacities, but this might also affect some other things, such as employment conditions. Subordinate auditors refer to that as a long-term issue. They noticed that significance of judgmental abilities might become shadowed in the near future. They also point that methodological procedures will have even more prominence in the audit industry in the future, which will have a major influence on what would be required from auditors.

Audit industry today implements more technology and methodology, and there is less and less responsibility for decisions and professional judgment to be applied. This makes not that bright people being needed, and using more non-experienced people in the process, and requiring more averaged quality employments in the 
audit industry. It will rather be that less skilled and experienced people will be required in an assurance service, and more commodity and tick-mark checking procedures to follow, rather than applying professional judgment and requiring professional expertise. (Interview with senior auditor, AF4/INT15)

Auditors using the tool are experiencing how the character of the tool, in fact, moderated expectations that superiors have from them. Actually, expectations are molded according to the tool-generated list of tasks, and the speed of fulfillment of prescribed tasks gauges superiors' satisfaction with an auditor.

Working "smarter" does not mean to implement or use more knowledge and more experience, it means just to get expected results faster, cheaper and easier. That's what basically means to work smarter, not harder. It is not required from you. Do not do more - just follow the procedure! (Interview with junior auditor, AF2/INT8)

Subordinate auditors acknowledged that the problem of professional judgment also influences the comfort, which they loose or no longer experience as technological capacitation constrain them to focus on tasks from the quality perspective. This could be related to the quality issues, but since the quality is ISA determined and translated into the form of audit procedures to guarantee the quality, rather than cognitive and emotional capacities of auditors suffer under technologically developed environment.

Now, we should rather follow the methodology and it doesn't matter if we don't have that big comfort, because we've done everything that the methodology said, and it should be fine. (Interview with senior auditor, AF1/INT2)

Finally, subordinate auditors seem to be professionally discouraged by the implementation of audit methodology into the ICT. The lack of professional challenges and opportunities to demonstrate judgmental capacities take their desires for professional development away. In general, the complexity of methodology might require longer adaptation and learn time. But, the stage when auditors become conscious about the consequences that the use of the tool brings to their professional development, actually, arrives when they get more experienced with it. That is the reason for a high turnover rate of among subordinate auditors, which differs from how the reason for leaving firm is interpreted by superior audit staff.

Do you like that approach? "No! So, that is what people don't like. A lot of people say that you can get five 'monkeys' and they will make it! Of course, it is not that simply stupid, but it becomes boring after some time and in many cases you feel like a little bit bind, you can't do what you would like to do. Actually, a lot of people don't like it, so that is why they leave the company. (Interview with senior auditor, AF2/INT7) 
In the overall of the previously presented findings in table 3 I provide with the outline of a number of quotations that have been extracted from interview protocols from the perspective of clusters of audit ranks. The respective number of quotations across different audit rank clusters is a reflection of the topics emerged from particular respondents rather than the actual number of individuals being interviewed.

\section{Tab. 3: An overview of quotations extracted from interview protocols across} audit firms and audit rank clusters

\begin{tabular}{lrrr}
\hline Audit firm & Superiors' quotes & Subordinates' quotes & In total \\
\hline 1 & 2 & 2 & 4 \\
2 & 4 & 3 & 7 \\
3 & 2 & 3 & 5 \\
4 & 2 & 2 & 4 \\
\hline In total & $\mathbf{1 0}$ & $\mathbf{1 0}$ & $\mathbf{2 0}$ \\
\hline
\end{tabular}

Source: authorial computation.

\section{Discussion}

This study is centred on the research question: How and why does the implementation of GAM into ICT impact the relationship between superiors and subordinates in Danish auditing context?

The discussion presents proposed answer to that question by presenting meanings of previously illustrated findings related to impacts of GAM and ICT on relations and interactions between auditors of different ranks. This section is organized around two previously outlined streams of literature, but it also gives several reflections to one of traditional auditing theories on sociality of comfort production developed by Pentland (1993). Results of the analysis are discussed through the perspective of a theoretical background of Giddens' (1990) modernity theory. I believe that such a combination of facets will give a sufficient number of reflections and provide the adequate answer to the research question.

The cross-sectional analysis of the implementation of global audit methodologies in information and communication technologies and their utilization across all Danish subsidiaries of Big 4 audit firms allowed identification of a type and nature of inner mechanisms of trusts, and challenges that prevalence in one type of it brought between different carriers of the profession. Those mechanisms enable gathering an insight on how two types of trusts in two trustworthy carriers of reembedded expert systems, the ICT-based tool and subordinate audit staff, are localized at the assurance context and why one of them has the prevalence over the other. In particular, the results here inspected the consequences of negotiations between trusts in carriers of the profession from the perspective of superior auditors, but the discussion was also supported by subordinates' points of view. In 
short, the data indicated that the tool has a constraining influence on users (subordinate auditors) in relation to administering the audit process, and thus provides the mechanism of a remote quality protection to superiors, which finally diminishes the necessity for interactions between auditors at different levels.

Early literature on implementation and utilization of the ICT and CAATTs identified that, in the auditing context, the use of technology as a tool may positively contribute to productivity and efficiency of auditors' performance during audit engagements (Abdolmohammadi \& Usoff, 2001; Banker et al., 2002; Elliot et al., 1985; Janvrin et al., 2008), and support almost any audit task (Pedrosa $\&$ Costa, 2012). But also, as presented above, the literature built on an alternative stream where scholars investigated impacts of technology and audit tools on professional judgment (Bell et al., 2002; Bonner, 1999), thoughts facilitation (Pieptea \& Anderson, 1987) and decision-making skills (Adler, 1987). What both of these streams of literature omitted to consider was the actual consequences of the ICT on the interaction between auditors at different ranks, and understanding mechanisms of why is that so. By filling that gap, this study contributes to the theory of information systems in auditing, as well to the auditing theory, as it suggests a technologically moderated model of the sociality of comfort production (see more Pentland, 1993).

Findings of this study do not aim at criticizing and substituting previous theoretical models. Rather, they contribute to a clearer and deeper understanding of why the presence of technology impacts relations and interactions between differently ranked auditors. Primarily, the study here confirms that integration of methodology in the ICT and utilization of it during audit engagement actually might increase productivity and efficiency, as it was previously argued by Abdolmohammadi \& Usoff (2001), Banker et al. (2002), Elliot et al., (1985) and Janvrin et al. (2008), however, in relation with ICT and CAATTs. At the same time, productivity and efficiency of GAM and ICT are positively acknowledged across both observed groups of audit ranks. Also, results here confirm that the tool might have a strong influence on the use and development of professional judgment skills as the tool prevents them from using and developing them, as it was previously argued by Bonner et al. (2002) and Bell (1999). In fact, the range of these initiatory findings represents the baseline upon which I extend the discussion in relation to the employed theoretical background, which enabled me to argue that two opposed mechanisms of trust and the prevalence in one of them affects social interactions and relations between auditors of different ranks.

Giddens' (1990) theory of modernity has provided this study to gather different perspective on understanding how and why productivity and efficiency incentives breed interaction issues. First of all, auditing environment is characterized by an unequal deployment of ICT-based audit tools across the range of audit ranks. The 
work environment of superior auditors is less or minimally exposed to technology, while subordinate auditors mainly work with the ICT. However, as superiors and subordinates are occupying opposite positions in regards to the exposure to the ICT, they are also expressing contrasting reflections on the utilization of it. The results show that both superior and subordinate auditors recognize that implementation of ICT-based tools positively impacts audit quality. This confirms that social actors, generally, are reliable to capacities of technology enable guarantee of quality. Replicating the Giddens' (1990) mechanisms of modernity, a trustworthiness of social actors towards the abstract capacities of the ICT, a disembedding mechanism, enables the mechanism of trust to become materialized at the time and space dimension of reality (particular context), and according to this theory, to become reembedded. Reembedding is the acceptance and integration of factual capacities of the particular abstract system to the local context as the trust in their functionality by social actors (superior auditors) is sufficient enough for the actual acceptance.

However, results further implied that the two ranks, in fact, have opposite incentives towards the use the ICT-based tool, which imposes a question of the source of those potentially conflicting incentives. Namely, the reason for such is that the tool now takes over the function of the main carrier of the audit profession, where subordinate auditors, which are primarily exposed to the use of it, perceive that they no longer have any influence on administering the audit process, since the tool moderates their actions and engagements. So, the source of conflicting incentives lies in differences between layers of trusts and in both groups of audit ranks. Namely, subordinates tend to express trust in their own professional capacities, as they perceive that there are more suitable carriers of the profession than the ICT-based tool. On the other hand, superiors, in fact, are negotiating between two types of trusts, in their subordinate staff and in the ICTbased tool, which results in the prevalence of the latter. From the theoretical point of view, this means that there is a negotiation between pros and cons of two distinctive scenarios. The negotiation contrasts strengths of reliability in carriers of the profession, namely human and the ICT. In both cases, carriers of profession play role in producing comfort to superiors, but in the first case human carriers are producing comfort by themselves that is further transferred to superiors, while in the second case the ICT carries the profession, thus eliminating potential for experiencing comfort by subordinates, while superiors still obtain the comfort that is now differently acquired in previous stages of the engagement. Thus, the results here show that superiors are trustier to the second case. This implies that their reliability is grounded on the integration of the expert system of audit profession into the expert system of the ICT. So, one expert system mediates the other and replaces human's mediation of the expert system of the profession, as fallible nature of human (see more: Zuboff, 1988) becomes replaced by the ICT. 
Therefore, that implies that technology as a carrier of a profession has prevalent trust over human capacities, which reduces needs to establish interaction and communication between auditors of different levels due to the distant controlling mechanism.

The emotional element involved in professional judgment, on the other hand, provides us with an alternative understanding of how interaction and relation model between differently ranked auditors is managed under newly established condition. Pentland's (1993) model of micro production of a macro order requires revision as embedding of an additional element disturbed previously depicted sociality of the macro order. In his interpretation, macro order emerges through sociality of gradually established comforts between differently ranked auditors, as interactions and relations between auditors of different levels enable transferability of comfort from lowest to the highest positioned auditors. Therefore, a macro order was, according to his argument, conditioned on hierarchy and personal relations and interactions between those hierarchies. However, when the tool becomes embedded to the hierarchy, it constrains reaching the state of comfort by subordinate auditors. Replacing the source of baseline comfort from social actors, as previous carriers of the profession, to the tool as a current one, in fact, substitutes pure social with techno-social gradualism of comfort. In this way lessened trust in human carriers of a profession implies that superiors' trust in technical aspects of work, being integrated into the ICT, neglects importance of interaction and establishing relations between auditors of different levels. This is due to the fact that trust in the ICT-based tool compensates subordinate's comfort and execution of tasks in ICT controlled environment, and giving sufficient comfort to superior auditors to generate the audit opinion.

\section{Conclusion}

The purpose of this study was to explore how and why interactions and relations between auditors at different ranks have been impacted by implementation of global audit methodology into information and communication technologies and their utilization into the audit processes. The analysis was based on inspection of auditors' perceptions in relation to the case at the assurance context. The paper here argued that prevailed trust in controlling and quality enabling capacity of the ICT-based tool (GAM integrated into ICT) displaces the source of comfort production from subordinate audit staff to the tool, which further diminishes the need for establishing interaction between superior and subordinate auditors. The data collected and analyzed in this study initially shows that both groups of audit ranks experiences positive implications of utilization of the ICT-based tool. But more interestingly, further analysis implies that their positive experiences soon get opposing tones as representatives are not exposed to the same circumstances and therefore do not have equal chances to perceive comfort. Therefore, superior 
auditors seem to be trustier to the ICT-based tool as a carrier of audit profession, since ICT as an expert system, which integrates the expert system of auditing enables them to be more comfortable with primarily mundane tasks, than when humans carry the profession. This still enables comfort, but only at the superior's part of the chain, and seemingly stronger than before. Hence, the results here stressed that audit quality tends not to be a product of a quality of professional skills of their practitioners, but rather reflects the technological capacities of the audit firm observed in the reduction of time necessary to produce audit opinion.

This article is grounded on the premise that interactions and relations between auditors in ICT environment are underresearched and undertheorized and that more knowledge and research are needed in order to understand how these interactions look like, and why is it so. To address the gap, this article used a theoretical background of a theory on modernity (Giddens, 1990). The theory takes two mechanisms, abstract and local (both based on trust), to break down all tangible elements that characterize the focal context, and through that enable understanding how and why trust enables functioning of social reality. These two theoretical mechanisms enabled me to reach the negotiation between trusts in two carriers of the expert system comfort and interaction at last. In such a manner conceptualized and understood context enabled me to discuss results with theories that proposed the model of social interaction in auditing, at the ICT-free environment.

The contribution of this study is twofold. At first, it gives a conceptual framework and therefore contributes to the literature on information and communication technology in auditing. Second, the study proposes a model of technologically moderated interaction as it reflects findings from the perspective of the theory on sociality of macro order production (Pentland, 1993). Besides the contributions to the theory, practitioners may also benefit from this study. It is important to stress that velocity of technological developments and prevalence in the auditing context in forthcoming years, as this might impact the profession of auditing as it may hit the development of the core property of the profession, a professional judgment. However, this study might give a universal insight to other types of professions, which have also been affected by utilization of technological advancements. The robotic nature of GAM might have an accelerating influence on increasing the level of risk of losing professional skills, as auditing has traditionally been considered as human-driven profession. Also, professional's awareness in technologically-driven quality of auditing increases the level of fluctuation of professionals, because efficiency is put in front of professional's knowledge and experience, which turns the quality of auditing into normative and standardized form, and independent from practitioners. 
Nevertheless, this study is not free of limitations. First and foremost the data collection took place within big audit environment but with a small set of participants in Denmark. Therefore, this research question requires more investigation. In particular, I would suggest more research among the second-tier audit firms (regional and local) as it might be fruitful for acknowledging the current issues existing in a small-scale audit firms, and how technologization has affected professionals at those levels. Also, a current state of methodological developments, for the type of study that aims at exploring relations and interactions between social actors, might urge for utilization of other types of methods. For example, current developments of a variety of methods on social network analysis and utilization of it to the studies of auditing may provide a better understanding of relations and the nature of those relations between social actors.

\section{References}

Abdolmohammadi, M., Usoff, C., 2001. A longitudinal study of applicable decision aids for detailed tasks in a financial audit. International Journal of Intelligent Systems in Accounting 3, 139-154, DOI: 10.1002/isaf.204.

Adler, P. S., 1987. Skill Formation in U.S. Accounting Firms: Pressures, Trends and Options. Journal of Technology and People 1, 3-16, DOI: 10.1108/eb022639.

Banker, R., Chang, H., Kao, Y., 2002. Discussion of Impact of Information Technology on Public Accounting Firm Productivity. Journal of Information Systems 2, 223-226. DOI: 10.2308/jis.2002.16.2.223.

Bell, T. B., Bedard, J. C., Johnstone, K. M., Smith, E. F., 2002. KRiskSM: A computerized decision aid for client acceptance and continuance risk assessments. Auditing 2, 96-113, DOI: 10.2308/aud.2002.21.2.97.

Berg, M., 1998. The Politics of Technology: On Bringing Social Theory into Technological Design. Science, Technology \& Human Values 4, 456-490, DOI: 10.1177/016224399802300406.

Bierstaker, J. L., Burnaby, P., Thibodeau, J., 2001. The Impact of Information Technology on the Audit Process: An Assessment of the State of the Art and Implications for the Future. Managerial Auditing Journal 3, 159-164, DOI: 10.1108/02686900110385489.

Bonner, S. E., 1999. Judgment and Decision-Making Research in Accounting. Accounting Horizons 1, 385-398, DOI: 10.2308/acch.1999.13.4.385.

Boyce, C., Neale, P., 2006. Conducting in-depth Interviews: A Guide for Designing and Conducting in-depth Interviews. Monitoring and Evaluation 2, 116. Available from: <http://www.cpc.unc.edu/measure/training/materials/dataquality-portuguese/m_e_tool_series_indepth_interviews.pdf>. [21 June 2016]. 
Brazel, J., Agoglia, C., Hatfield, R., 2004. Electronic vs. Face-to-face Review: The Effects of Alternative Forms of Review on Auditors' Performance. The Accounting Review 4, 949-966, DOI: 10.2308/accr.2004.79.4.949.

Charmaz, K., 2006. Constructing Grounded Theory: A Practical Guide Through Qualitative Research. London, SAGE Publications Ltd.

Corbin, J. M., Strauss, A., 1990. Grounded Theory Research: Procedures, Canons, and Evaluative criteria. Qualitative Sociology 1, 3-21, DOI: 10.1007/bf00988593.

Dowling, C., 2009. Appropriate Audit Support System Use: The Influence of Auditor, Audit Team, and Firm Factors. The Accounting Review 3, 771-810, DOI: 10.2308/accr.2009.84.3.771.

Dowling, C., Leech, S., 2007. Audit Support Systems and Decision Aids: Current Practice and Opportunities for Future Research. International Journal of Accounting Information Systems 2, 92-116, DOI: 10.1016/j.accinf.2007.04.001.

Eisenhardt, K. M., 1989. Building Theories from Case Study Research. Academy of Management Review 4, 532-550, DOI: 10.5465/amr.1989.4308385.

Eisenhardt, K. M., Graebner, M. E., 2007. Theory Building From Cases: Opportunities and Challenges. Academy of Management Journal 1, 25-32, DOI: 10.5465/amj.2007.24160888.

Elliot, R., Kielich, J., Marwick, P., 1985. Micros in Accounting. Expert Systems for Accountants 3, 126-134.

Giddens, A., 1990. The Consequences of Modernity. Stanford University Press. Glaser, B., Strauss, A., 1967. The Discovery of Grounded Theory: Strategies for qualitative research. Aldine Transaction, A Division of Transaction Publishers.

Glover, S. M., Prawitt, D. F., Spilker, B. C., 1997. The Influence of Decision Aids on User Behavior: Implications for Knowledge Acquisition and Inappropriate Reliance. Organizational Behavior and Human Decision Processes 2, 232-255, DOI: 10.1006/obhd.1997.2735.

IFAC, 2009. International Standard on Auditing (ISA) 315. Identifying and Assessing the Risk of Material Misstatement Through Understanding the Entity and its Environment, IAASB.

Janvrin, D., Bierstaker, J., Lowe, D. J., 2008. An Examination of Audit Information Technology Use and Perceived Importance. Accounting Horizons 1, 1-21, DOI: 10.2308/acch.2008.22.1.1.

Langley, A. et al., 2013. Process Studies of Change in Organization and Management: Unveling Temporality, Activity and Flow. Academy of Management Journal 1, 1-13, DOI: 10.5465/amj.2013.4001. 
Manson, S., McCartney, S., Sherer, M., 2001. Audit Automation as Control Within Audit Firms. Accounting, Auditing \& Accountability Journal 1, 109-130, DOI: $10.1108 / 09513570110381097$.

O'Leary, D. E., Watkins, P. R., 1989. Review of Expert Systems in Auditing. Expert Systems Review 2, 3-22.

Omoteso, K., Patel, A., Scott, P., 2010. Information and Communications Technology and Auditing: Current Implications and Future Directions. International Journal of Audit 14, 147-162. DOI: 10.1111/j.10991123.2009.00410.x

Orlikowski, W. J., Iacono, C. S., 2001. Research Commentary: Desperately Seeking the "IT" in IT Research - A Call to Theorizing the IT Artifact. Information Systems Research 2, 121-134, DOI: 10.1287/isre.12.2.121.9700.

Pedrosa, I., Costa, C. J., 2012. Computer Assisted Audit Tools and Techniques in Real World: CAATT's Applications and Approaches in Context. International Journal of Computer Information Systems and Industrial Management Applications 4, 161-168.

Pentland, B. T., 1993. Getting Comfortable with the Numbers: Auditing and the Micro-production of Macro-order. Accounting, Organizations and Society 7-8, 605-620, DOI: 10.1016/0361-3682(93)90045-8.

Pieptea, D., Anderson, E., 1987. Price and Value of Decision Support Systems Comments. MIS Quarterly 4, 515-528, DOI: 10.2307/248981.

Robson, K., Humphrey, C., Khalifa, R., Jones, J., 2007. Transforming Audit Technologies: Business Risk Audit Methodologies and the Audit Field. Accounting, Organizations and Society 4-5, 409-438, DOI: 10.1016/j.aos.2006.09.002.

Sorensen, J. E., Sorensen, T. L., 1974. The Conflict of Professionals in Bureaucratic Organizations. Administrative Science Quarterly 1, 98-106, DOI: $10.2307 / 2391790$.

Stones, R., 2012. Disembedding. The Wiley-Blackwell Encyclopedia of Globalization 1-2, 1-2.

Swinney, L., 1999. Consideration of the Social Context of Auditors' Reliance on Expert System Output During Evaluation of Loan Loss Reserves. International Journal of Intelligent Systems in Accounting, Finance \& Management 3, 199-213, DOI: 10.1002/(sici)1099-1174(199909)8:3<199::aid-isaf160>3.0.co;2-a.

Weiss, Robert S., 1994. Learning From Strangers: The Art and Method of Qualitative Interview Studies. New York, Free Press.

Yin, R. K., 2011. Qualitative Research from Start to Finish. New York, The Guilford Press. 
Kacanski, S.: $\quad$ ICT in Auditing: Impact of Audit Quality Norms on Interpersonal Interactions.

Zuboff, S., 1988. In the Age of the Smart Machine: The Future of Work and Power. New York, Basic Books. 